\title{
AGING EFFECTS AND GENERATIONAL DIFFERENGES IN SOCIAL WELFARE ATTITUDE CONSTRAINT IN THE MASS PUBLIG
}

\author{
SAMUel A. KIRKPatrick \\ University of Oklahoma
}

$\mathrm{T}$

wo prominent heuristic forces prevailing in both scholarly social science research and popular commentary during the past two decades include arguments over the end of ideology and assessments of generation gap phenomena. Neither concern is amenable to simplistic treatment, yet much of the dialogue and evidence in both scholarly areas has developed in an atmosphere of mutual exclusiveness. Political scientists and sociologists have expressed a concern for both, yet the latter have been more uniquely concerned with generational differences; the ideology school includes a concern for normative issues whereas generation gap research tends to be either "popular" or more analytical; and divergent methodologies characterize each. As a result, we have only recently begun to build bridges between schools - to investigate the necessary linkages between generational phenomena and issues of ideology. It is this potential linkage between two large, conflicting and amorphous schools of thought which serves as an initial motivating force for the research reported here.

In oversimplified terms, concern over the end of ideology construct ${ }^{1}$ - and more specifically, over the irrationality, inconsistency, and low awareness supposedly characteristic of mass publics in the United States - resulted in a crystallizing body of research pointing to cognitive capabilities of the average citizen, attitude consistency, structural integration of belief systems, and issue voting. ${ }^{2}$ Although heated debate continues over various conceptualizations, types of measurement, and analysis techniques applied to the study of mass public belief systems ${ }^{3}$ and levels of

Note: An earlier version of this paper was presented at the Annual Meeting of the American Political Science Association, Chicago, August 29-September 2, 1974. I gratefully acknowledge the assistance of Gary L. Cathey and Michael Hall in the tabulation and preparation of cohort matrices, and helpful comments from William Klecka and Neal Cutler.

"For general treatments see Giovanni Sartori, "Politics, Ideology, and Belief Systems," American Political Science Review, 63 (1969), 398-411; Willard A. Mullins, "On the Concept of Ideology in Political Science," American Political Science Revieze, 66 (1972), 498-511; Giuseppe DiPalma, The Study of Conflict in Western Society (Morristown, N.J.: General Learning Press, 1973); Daniel Bell, The End of Ideology (New York: Collier, 1962).

${ }^{2}$ The literature on these subjects is rapidly expanding, for a review of belief systems see Stephen Earl Bennett, "Consistency Among the Public's Social Welfare Policy Attitudes in the 1960s," Midwest Journal of Political Science, 17 (1973), 544-570; Samuel A. Kirkpatrick, "Conflicts in Political Attitudes: Behavioral and Dynamic Consequences," in Samuel A. Kirkpatrick and Lawrence K. Pettit, eds., The Social Psychology of Political Life (North Scituate, Mass.: Duxbury, 1972), pp. 342-60; John C. Pierce and Douglas D. Rose, "Nonattitudes and American Public Opinion: The Examination of a Thesis," American Political Science Review, 68 (1974), 626-50; and for issue voting see generally Gerald M. Pomper, "From Confusion to Glarity: Issues and American Voters, 1956-1968," American Political Science Review, 66 (1972), 415-28; John H. Kessel, "Comment: The Issues in Issue Voting," American Political Science Review, 66 (1972), 459-65; Samuel A. Kirkpatrick and Melvin E. Jones, "Issue Publics and the Electoral System: The Role of Issues in Electoral Change," in Allen R. Wilcox, ed., Public Opinion and Political Attitudes (New York: Wiley, 1972), pp. 537-55.

${ }^{3}$ Especially Pierce and Rose, "Nonattitudes"; Philip E. Converse, "Comment: The Status of Nonattitudes," American Political Science Review, 68 (1974), 650-60; Douglas D. Rose and John C. Pierce, "Rejoinder to "Comment' by Philip E. Converse," American Political Science Review, 68 (1974), 661-66; Bernard C. Hennessy, "A Headnote on the Existence and Study of Political Attitudes," Social Science Quarterly, 51 (1970), 46376; Samuel A. Kirkpatrick, "Political Attitude Structure and Component Change," Public Opinion Quarterly, 34 (1970), 403-7; Eugene Litwak, Nancy Hooyman, and Donald Warren, "Ideological Complexity and Middle-American Rationality," $P u b l i c$ 
political issue relevance, ${ }^{4}$ there appears to be an emerging agreement over increases in "ideology-related" belief structures and subsequent behavior in the American public. One of the most comprehensive statements on these matters is found in Bennett ${ }^{5}$ and his attempt to replicate the "constraint among idea-elements" construct originally developed by Converse. ${ }^{6}$ His recent findings on increasing levels of attitude constraint among social welfare issues in the 1960 s serves as a baseline for our departure.

A second point of departure logically follows substantive findings pointing to increased constraint. The explanatory framework for these shifts focuses on rapid sociopolitical change and the growing political turmoil and cleavage of the $1960 \mathrm{~s}^{7}$ That is, both social welfare belief consistency and issue voting (as well as partisan realignment discussions) rely on explanations tied to political events in recent years. Such interpretations dovetail nicely with growing bodies of literature on generational differences and youth culture, i.e., a class of interpretations implicitly linking generation and period explanations to increased ideological awareness. ${ }^{8}$

The above trend cited for the mass public, plus the interpretive linkage to events, highlights the basic research question for this study: Does the trend toward increased issue constraint, usually explained in terms of generational differences and events common to historical periods, hide underlying ontogenetic qualities linked to changes over the life-cycle? More specifically, is birth cohort succession, whereby older, less ideological generations 'die off' to be replaced by more issueaware and event-influenced younger generations, accompanied by aging effects, whereby movement through the life-cycle promotes increased consistency within belief systems? Although either set of influences is not likely to occur independent of the other, the aging hypothesis has been seriously neglected and the relevant research literature in both political science and sociology suggests a complexity heretofore uninvestigated in the analysis of changing levels of belief system integration.

\section{Generational and Life-Cycle Effects in Politics}

Theoretical concerns and empirical evidence about the complex influences of aging and generational changes in politics are fairly recent issues. Unfortunately, they are largely dependent on research in political science characterized by isolated cross-section analyses and inattention to age-related differences; and on sociological research preoccupied with concerns more unique to "social gerontology" and less related to political perspectives on attitudes and ideology. ${ }^{9}$ Irrespective of these limitations, relevant pieces of evidence can be garnered from single cross-section

Opinion Quarterly, 37 (1973), 317-33; George E. Marcus, David Tabb, and John L. Sullivan, "The Application of Individual Differences Scaling to the Measurement of Political Ideologies," American Journal of Political Science, 18 (1974), 405-20.

"See Kessel, "Comment," for a summary of divergent approaches to issue voting.

"Bennett, "Consistency." Also see Norman H. Nie and Kristi Andersen, "Mass Belief Systems Revisited: Political Change and Attitude Structure," Journal of Politics, 36 (1974), 540-92 for supporting data on constraint between issue domains.

"Philip E. Converse, "The Nature of Belief Systems in Mass Publics," in David E. Apter, ed., Ideology and Discontent (New York: Free Press, 1964), pp. 206-61.

"Bennett, "Consistency"; Herbert F. Weisberg and Jerrold G. Rusk, "Dimensions of Candidate Evaluation," American Political Science Review, 64 (1970), 1167-85; Samuel A. Kirkpatrick and Melvin E. Jones, "Vote Direction and Issue Cleavage in 1968," Social Science Quarterly, 51 (1970), 689-705.

s Although I use "ideology" loosely here, I recognize the wealth of viewpoints about its meaning; cf. Samuel A. Kirkpatrick, "Political Attitudes and Behavior: Some Consequences of Attitudinal Ordering;" Midwest Journal of Political Science, 14 (1970), 1-24.

${ }^{2}$ Note the paucity of studies related to political attitudes compared to those on stratification and roles in Matilda White Riley and Anne Foner, Aging and Society (New York: Russell Sage, 1968), Vol. 1. 
analyses incorporating age as a variable, research on parent-child socialization, social gerontology, and cohort analyses of sets of cross-section surveys.

Although popular commentary and recent research in the late 1960s tends to support generational differences in political life, many early inquiries emphasized enduring loyalties, stability, and generational similarities. ${ }^{10}$ As political scientists posed change-related inquiries, however, generational differences became the focus for interpretation - as evidenced in explanations of partisan choice. ${ }^{11}$ But the comparative base for intepretation was generational similarities versus dissimilarities, i.e., the potential impact of changes with aging was avoided except in crosssection analyses of voter turnout. ${ }^{12}$

Political socialization research has been cast in similar terms, often precluding anything but generation-related interpretations. Findings in support of generation gap hypotheses show weak group correspondences between aggregates of parents and children with regard to (1) political involvement, ${ }^{1.3}$ (2) political cynicism, ${ }^{14}$ and (3) a host of sociopolitical attitudes measured in the late $1960 \mathrm{~s}^{15}$ On the other hand, socialization effects are best measured by paired correspondences in matched parent/child dyads accompanied by group correspondences - and this only holds for party preference. ${ }^{16}$ That is, only party affiliation is transmitted via socialization mechanisms which enforce similarities between generations. Connell ${ }^{17}$ suggests that this holds for party preference because an established institution is the attitude object. On the whole, his review of parent-child socialization research indicates that "older and younger generations have developed their opinions in parallel rather than in series, by similar experiences in a common way of life."18 This conclusion is based on high group correspondences between generations on a wide range of social and political measures from 1944 to 1968 . Therefore, with the exception of political cynicism, involvement and recent changes in the late 1960s, similarities between generations are prevalent, but not due to socialization effects. Yet are we willing to contend that a way of life is so common as to impose intergenerational homogeneity? Although that is the implication from socialization studies, they also fail to support the possibility of aging effects by theoretically imposing homogeneity within generations through two basic contentions: that childhood learning is enduring and that basics acquired early provide structure for

${ }^{10}$ See Byron G. Massialas, Education and the Political System (Reading, Mass.: AddisonWesley, 1969), Chapter 2.

${ }^{11}$ Angus Campbell et al., The American Voter: An Abridgment (New York: Wiley, 1964), pp. 90-96; Philip E. Converse, "Of Time and Partisan Stability," Comparative Political Studies, 2 (1969), 139-71; for a cohort analysis supporting a generational interpretation of the relationship between class and partisan choice see Paul R. Abramson, "Generational Change in American Electoral Behavior," American Political Science Revieze, 68 (1974), 93-106.

12 The relationship is somewhat curvilinear, see Campbell et al., American Voter, pp. 261-65; for a cohort analysis see William R. Klecka, "Applying Political Generations to the Study of Political Behavior," Public Opinion Quarterly, 35 (1971), 358-73.

${ }^{\text {ss }}$ Eugene S. Uyeki and Richard W. Dodge, "Generational Relations in Political Attitudes and Involvement," Sociology and Social Research, 48 (1964), 155-65.

${ }^{14}$ M. Kent Jennings and Richard G. Niemi, "The Transmission of Political Values from Parent to Child," American Political Science Review, 62 (1968), 159-84.

${ }^{26}$ Lucy N. Friedman, Alice R. Gold, and Richard Christie, "Dissecting the Generation Gap: Intergenerational and Intrafamilial Similarities and Differences," Public Opinion Quarterly, 36 (1972), 334-47; they also note that the younger generation was more consistent, p. 345 .

${ }^{16}$ Jennings and Niemi, "Transmission."

${ }^{17}$ R. W. Connell, "Political Socialization in the American Family: The Evidence Reexamined," Public Opinion Quarterly, 36 (1972), 323-34.

${ }^{18}$ Ibid., p. 330. This research on two generations cannot assess the weakening transmission of beliefs across several generations as suggested by Paul Allen Beck, "A Socialization Theory of Partisan Realignment," in Richard G. Niemi, ed., The Politics of Future Citizens: New Dimensions in Socialization (San Francisco: Jossey-Bass, 1974). 
later specific issue beliefs. ${ }^{19}$ Only recent empirical research on the absence of the latter "structuring principle" and the lack of association between early orientations and later issue orientation may "correct" this strange socialization tautology and facilitate an alternative aging interpretation. ${ }^{20}$

Social gerontology research offers a different perspective on the issue of maturation and generation effects by emphasizing aging, usually to the exclusion of other factors. More specifically, controversies over the disengagement thesis directed attention to aging as a variable relevant in politics. Early findings supported opinionation and participation decline with aging, ${ }^{21}$ but displayed a tendency for the elderly to establish internal consistency, ${ }^{22}$ congruence between personal opinions and those ascribed to others, ${ }^{23}$ stabilization and routinization, ${ }^{24}$ and better knowledge skills. ${ }^{25}$ In addition, more recent cohort analyses have supported an increase in opinionation and attention with aging, ${ }^{26}$ greater involvement in politics, ${ }^{27}$ or no decrease in voting turnout. ${ }^{28}$

Although more specific and current attempts to isolate generational and maturation effects through cohort analysis have not focused directly on changing belief structures, a repertoire of findings on political matters illustrates the mixture of effects and the unsettled issues of a growing school of analysis. In addition to those on turnout mentioned above (noting the importance of aging effects), ${ }^{29}$ political cohort analyses focus on (1) partisan attachment; (2) political issues; and (3) political powerlessness and estrangement. Although controversy endures over differential effects on partisanship, early support for the "aging Republican" hypothesi $\mathrm{s}^{30}$ has diminished in light of evidence either supporting generational differences, ${ }^{31}$ or pointing to no consistent effect either way. ${ }^{32}$ Judgments about the

\footnotetext{
${ }^{19}$ See the review by Donald D. Searing, Joel J. Schwartz and Alden E. Lind, "The Structuring Principle: Political Socialization and Belief Systems," American Political Science Revier, 67 (1973), 415-33.
}

${ }^{20}$ Ibid.

${ }^{21}$ Kenneth J. Gergen and Kurt W. Back, "Aging, Time Perspective and Preferred Solutions to International Conflicts," Journal of Conflict Resolution, 9 (1965), 177-86; Frank Pinner, "Theories of Political Participation and Age," in Wilma Donahue and Clark Tibbetts, eds., Politics of Age (Ann Arbor: University of Michigan Press, 1962), p. 65.

${ }^{22}$ Charlotte Buhler, "Meaningful Living in the Mature Years," in R. Kleeman, ed., Aging and Leisure (New York: Oxford University Press, 1961).

${ }^{23}$ Bernice L. Neugarten, Joan W. Moore, and John C. Lowe, "Age Norms, Age Constraints, and Adult Socialization," American Journal of Sociology, 70 (1968), 717.

${ }^{24}$ Norman B. Ryder, "The Cohort as a Concept in the Study of Social Change," American Sociological Review, 30 (1965), 843-61.

${ }^{25}$ James E. Birren and Donald F. Morrison, "Factors in the Organization of Mutual Abilities with Advancing Age," in Richard Williams et al., Processes of Aging: Social and Psychological Perspectives (New York: Atherton Press, 1963), Vol. 1, p. 14.

${ }^{26}$ Norval D. Glenn, "Aging, Disengagement, and Opinionation," Public Opinion Quarterly, 33 (1969), 17-33; also see Herbert H. Hyman, Secondary Analysis of Sample Surveys (New York: Wiley, 1972), pp. 264-74.

${ }^{2 n}$ John Crittenden, "Aging and Political Participation, Western Political Quarterly, 16 (1963), 323-31.

${ }^{28}$ Norval D. Glenn and Michael Grimes, "Aging, Voting, and Political Interest," American Sociological Review, 33 (1968), 563-75.

${ }^{29}$ Also see Klecka, "Applying Political Generations."

so John Crittendon, "Aging and Party Affiliation," Public Opinion Quarterly, 26 (1962), $648-57$

${ }^{31}$ Neal Cutler, "Generation, Maturation and Party Affiliation: A Cohort Analysis," Public Opinion Quarterly, 33 (1970), 583-88; Norval D. Glenn and Ted Hefner, "Further Evidence on Aging and Party Identification," Public Opinion Quarterly, 36 (1972), 3247. This controversy is particularly difficult to analyze since Cutler avoids a trend correction and Glenn and Hefner argue that such a correction by Crittenden makes aging effects pronounced. For a discussion see Samuel A. Kirkpatrick, Quantitative Analysis of Political Data (Columbus, Ohio: Merrill, 1974), pp. 465-66. Also note a critique of Glenn and Hefner for avoiding period effects, Karen Oppenheim Mason et al." "Some Methodological Issues in Cohort Analyses of Archival Data," American Sociological Review, 38 (1973), 242-58. For related research see Abramson, "Generational Change"; 
direction of attitudes on political issues have engendered less controversy, yet the field is considerably underdeveloped. Glenn and Hefner ${ }^{33}$ infer the absence of an "aging conservative" effect from data on partisanship, yet they offer some support for an "aging liberal" interpretation. Klecka's analysis of specific issues supports a generational interpretation for changes on aid to education attitudes, yet both effects are present at different stages when isolationist attitudes are the focus for inquiry. ${ }^{34}$ Finally, various forms of political powerlessness and estrangement appear to be influenced by both effects: some aspects of political efficacy show a decrease in powerlessness as young cohorts age to a middle-age plateau with subsequent increases for older cohorts, while support for voting as the sole influencing mechanism in the political system is tied to generational changes $;^{35}$ and somewhat contrary evidence notes both effects in trends toward estrangement with aging among the youngest and oldest cohorts, with maturation influences emphasized. ${ }^{36}$

Although comparisons such as the above are difficult in light of analysis differences even within the cohort school, the weight of evidence is away from aging effects in political life and toward interpretations emphasizing generational differences or mixed effects. Furthermore, there is little direct evidence in either attitude theory or social gerontology which would support the predominance of either effect in the analysis of changing belief systems.

\section{Research Design}

As noted earlier, a variety of belief system conceptualizations and subsequent measurements are available for analysis, yet the research design employed here closely follows the prevalent constraint model as originally developed by Converse and extended by Bennett. ${ }^{37}$ It therefore employs mean gamma coefficients within an issue domain as an indication of constraint, i.e., the ability to predict one attitude in a domain from another. Following Bennett, attitudes toward social welfare policies are traced longitudinally in the American public, with measures of constraint developed for each observation period. It departs from Bennett's replication of Converse by further extending the social welfare domain into the mid1950s from the late 1960s through the use of four Survey Research Center Presidential Election Surveys from 1956 to $1968 .^{38}$ Further extensions to available data in 1952 or 1972 are impossible given research discontinuities on political issue variables, yet comparability over twelve years is possible for three core social welfare issues dominating the era: government responsibility for employment, govern-

Norval D. Glenn, "Sources of the Shift to Political Independence: Some Evidence from a Cohort Analysis," Social Science Quarterly, 53 (1972), 494-520; Norval D, Glenn, "Class and Party Support in the United States: Recent and Emerging Trends," Public Opinion Quarterly, 37 (1973), 1-21.

"Klecka, "Applying Political Generations."

"Glenn and Hefner, "Further Evidence."

"Klecka, "Applying Political Generations."

${ }^{25}$ Thomas J. Agnello, Jr., "Aging and the Sense of Political Powerlessness," Public Opinion Quarterly, 37 (1973), 251-60.

"Arthur H. Miller, Thad A. Brown, and Alden S. Raine, "Social Conflict and Political Estrangement, 1958-1972," unpublished paper presented at the Annual Meeting of the Midwest Political Science Association, 1973.

${ }^{37}$ Converse, "The Nature of Belief Systems in Mass Publics"; Bennett, "Consistency" ; also see Norman R. Luttbeg, "The Structure of Beliefs Among Leaders and the Public," Public Opinion Quarterly, 32 (1968), 398-409.

ss Bennett, "Consistency," included 1964 and 1968 SRG data in his text, with footnote references to earlier studies supporting an increase over Converse's 1958 data to insure that increases were not due to falsely depressed values in an off-year election study. The data utilized here were made available by the Inter-University Consortium for Political Research. They include the major presidential election studies for 1956 through 1968 originally collected by the Survey Research Center at the University of Michigan. Neither the Center nor the Consortium bear any responsibility for the analysis or interpretation presented here. 
ment-insured medical care, and federal aid to education. ${ }^{39}$ Although Bennett's issue domain includes general attitudes toward the power of the federal government, it was not measured in 1956 or 1960, and it appears to elicit responses of a more general nature such that they may "over-integrate" a more specific policy domain. ${ }^{40}$ Such attempts at longitudinal extensions, however, cannot be accomplished with perfect comparability in response categories: the 1968 SRC study employs a three-category response code whereas earlier ones assessed a five-point range. Since Bennett focuses on only two years (1964 and 1968), he opts to reduce 1964 response categories in order to achieve paired comparability. But this is a more serious issue for the analysis employed here since substantial amounts of information would be lost, variance reduced, and gamma coefficients inflated by greater ties. ${ }^{41}$ As a consequence, less than perfect comparability in response codes between 1964 and 1968 must endure over the loss of data. ${ }^{42}$

In the absence of a long-term panel of respondents, the nature of constraint change and the isolation of age-related impacts may nevertheless be judged through the application of cohort analysis. This "quasi-panel" approach traces birth cohorts or generations as aggregates of individuals across various observation periods. Although individual-level generalizations are tenuous, those based on generations provide more detail and enable us to avoid the age-related fallacies associated with cross-section analysis. ${ }^{43}$ The latter is especially open to misinterpretation and the commission of fallacies. One of the basic difficulties is the isolation of generation versus maturation effects; therefore, a generational fallacy may be committed by overlooking the aging process (as much research on politics attests), or a life course fallacy may be committed by overlooking cohort differences (as evidenced in socialization research). But cohort analysis itself neither guarantees the accurate isolation of effects (witness the above controversies) nor the avoidance of fallacies. If no attention is paid to relative cohort size, a proportional representational fallacy is likely if a particular weight is attributed to one generation over another. Since we have no interest in such an assessment here, cohort size is permitted to vary. Furthermore, a compositional fallacy is possible when cohort change with replacement contains a specific bias on a variable mediating age and the dependent measure. ${ }^{44}$ Tabular controls assist in this difficulty; they are employed for educational level later in the analysis.

In summary, the design for constraint measurement and analysis closely follows recent research efforts with substantial continuity suggesting important increases during the $1960 \mathrm{~s}$. It then employs cohort analysis to interpret the validity of eventimpact hypotheses uniformly applied to constraint explanations. ${ }^{45}$ This technique

See SRC codebooks for minor variations in phraseology.

${ }^{40}$ For problems with this question see Kessel, "Comment"; Kirkpatrick and Jones, "Vote Direction and Issue Cleavage in 1968"; Samuel A. Kirkpatrick, "Issue Orientation and Voter Choice in 1964," Southwestern Social Science Quarterly, 40 (1968), 87-102.

${ }^{4}$ See Kirkpatrick, Quantitative Analysis of Political Data, pp. 47-48. As in Bennett and Converse, the gamma is calculated across meaningful codes only.

"2 Bennett, "Consistency," p. 555, footnote 41 reports only "minor variations" in results between five and three code items, yet three codes obviously inflate the coefficients somewhat over the three comparable social welfare issues for 1964; Bennett's mean gamma $=.56$.

"For general treatments of cohort analysis see Ryder, "The Cohort"; William M. Evan, "Cohort Analysis of Survey Data: A Procedure for Studying Long-Term Opinion Change," Public Opinion Quarterly, 23 (1959), 63-72; Kirkpatrick, Quantitative Analysis of Political Data, pp. 406-409; Hyman, "Secondary Analysis," pp. 274-90.

${ }^{44}$ For a discussion of fallacies see Matilda White Riley, "Aging and Cohort Succession: Interpretations and Misinterpretations," Public Opinion Quarterly, 37 (1973), 35-50.

${ }^{45}$ But these explanations do not argue for generation effects over aging, they merely avoid life cycle questions and emphasize short-term forces. The presence of aging, generation and possible short-term period effects makes it very difficult to isolate "unique" effects in a statistical fashion; see Mason et al., "Some Methodological Issues." 
facilitates theoretical and empirical distinctions between (1) the process of aging whereby individuals change psychologically and physiologically, passing through different societal roles influenced by age stratification in a culture; and (2) the process of cohort flow, succession and replacement through which new cohorts of respondents are born, by which generations start political careers and experiences in different climates, and through which individuals experience unique events which have lasting impact so as to facilitate similarities within generations and differences between them. ${ }^{46}$

\section{Age-Related Differences in Sogial Welfare Attitude Constraint}

Since the foregoing methodological issues create minor differences between data analyzed by Bennett and that reported here, Table 1 presents the inter-item gamma coefficients that entered the cohort analysis as domain means for the total population and age subgroups. A progressive increase in inter-item constraint is evident over time for the entire sample; the only erratic deviation within the domain is a drop in response consistency for the aid to education/employment dyad for 1964.47 The total means summarizing coefficients in Table 1 appear at the bottom of Table 2. Both the individual and summary measures are supportive of Bennett's higher coefficients for the 1960s. While only one individual measure is comparable to Converse's 1958 data, ${ }^{48}$ his .45 gamma value for employment and education fits the overall trend nicely. Although Bennett relied primarily on 1964 and 1968 cross-sections and their comparison with off-year values in 1958 as re-

Table 1. Social Welfare Attitude Constraint (gamma)

for the American Public: 1956-1968

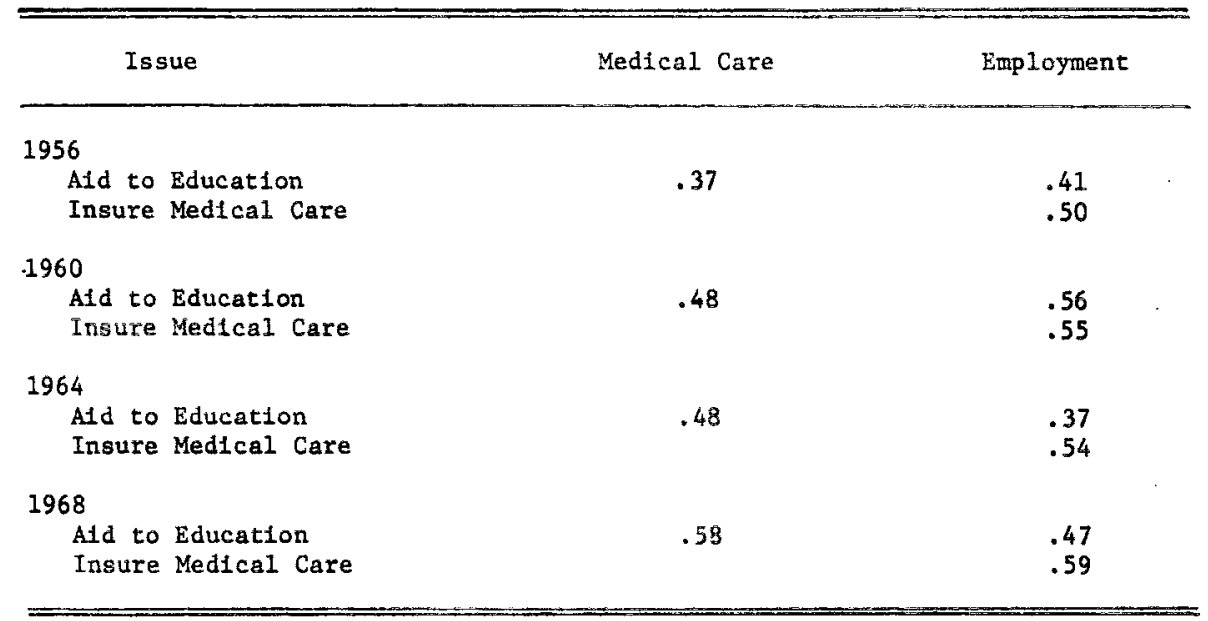

"See Riley, "Aging and Cohort Succession"; Anne Foner, "Age Stratification and Age Con" flict in Political Life," American Sociological Review, 39 (1974), 187-97; Leonard D. Cain, Jr., "Life Course and Social Structure," in Robert E. L. Faris, ed., Handbook of Modern Sociology (Ghicago: Rand McNally, 1964), pp. 272-309. Such an inquiry does not suggest that aging effects necessarily cause cross-sectional trends. If the proportion of the population at each age level remains constant, progress through the lifecycle has no impact on total population trends. Nevertheless, as age groups shift in their relative contribution to the population as a whole - as evidenced in the United States in the $1950 \mathrm{~s}$ and $1960 \mathrm{~s}$ primarily among the young and aged - and as aging effects may occur disproportionately from group to group (i.e., interact with generational differences), there is a potential impact on trends. In addition, certain classes of aging or generational effects could be present with or without a trend for the total population.

"This is part of a slight depression across the sample.

4 The mean gamma value for the total domestic domain, including civil rights issues in 1958 was .23 . 
ported by Converse, the extensions reported here reconfirm his findings with as much empirical certainty as is possible. ${ }^{49}$ We now turn to the issue of age-related differences hidden in Table 1 and the central tendency measures.

Table 2 presents mean gamma coefficients in a cohort matrix facilitating judgments about aging and generational effects. By reading down each column in a cohort matrix differences between age groups may be noted for each crosssection and a comparison of columns across rows notes possible changes in the patterns for age groups. But each cohort or generation represented by diagonals (e.g., respondents 21 to 24 years old in 1956 who are 25 to 28 years old in 1960 , etc.) may be read to assess the aging phenomenon, whereas diagonals are compared to note generational differences and the impact of historical events. In summary, three confounding effects are theoretically present (with two intepretable at a time ${ }^{50}$ ): (1) pure period effects (e.g., caused by an election) would create perfect homogeneity among the age groups for each cross-section, with differences from year to year (election to election); (2) pure aging effects would impose

Table 2. Cohort Matrix of Social Welfare Attitude Constraint ( $\overline{\mathrm{X}}$ gamma) for the American Public: 1956-1968

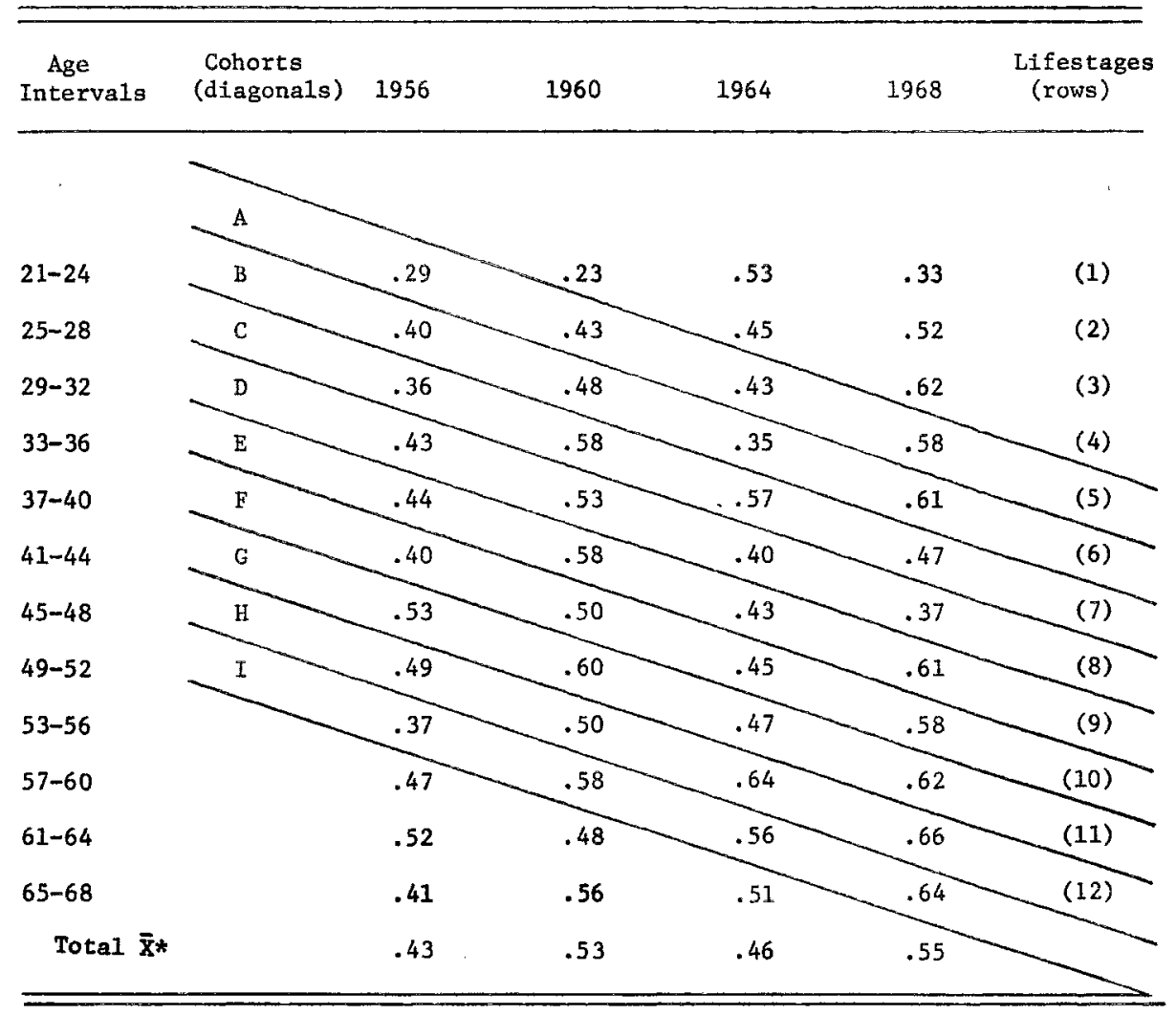

*The mean gamma coefficient for three soclal welfare polfcies across the total sample, i.e., grand trend values.

4 The mean gammas for Bennett's domestic social welfare domain $=.54$ (1964) and .51 (1968) with the government power item included; also see Bennett, p. 557, footnote 47 for mean gammas excluding power and including equal job opportunities for Blacks, .38 $(1956), .42(1960), .52(1964), .57$ (1968).

"See Mason et al., "Some Methodological Issues"; Paul B. Baltes, "Longitudinal and CrossSectional Sequences in the Study of Age and Generation Effects," Human Development, 11 (1968), 145-71. 
homogeneity within each row (lifestage) and heterogeneity (linearity) within the cohort diagonals; and (3) pure generational or cohort effects would be evidenced by perfect homogeneity within each diagonal and heterogeneity (linearity) within each lifestage.

A visual inspection of Table 2 shows few period effects, i.e., differences between the years and homogeneity within each year across age groups. Of course, such an interpretation would imply no differences between age groups, i.e., a uniform impact of some event at the time of observation. Even those suggesting that events in the 1960s heightened cleavages, awareness and constraint, would surely not subscribe to the absence of age-related differences. But events can influence constraint in another way: by shaping higher levels among younger generations passing through their formative years in the 1960 s. There is little evidence for this effect since complete cohorts are unavailable for this generation and the data that do bear from Table 2 (above the top diagonal) are mixed. Another possibility for generational differences and event influences suggests that such differences exist among certain cohorts, even though formative socialization influences cannot operate. Such an effect would be striking if certain cohorts were characterized by homogeneous constraint levels of different magnitude than other generations. According to Table 2, they are not so striking and there is evidence for aging changes measured by the general increase in constraint level as a generation matures. Yet there are some generational differences: the older generations have higher constraint levels, although they were already higher in 1956 compared to the youngest cohorts.

Most important, there is strong evidence for a mixture of effects: while there is a tendency for older generations to be characterized by higher constraint, aging effects occur among both the youngest and oldest cohorts. For example, the oldest complete cohorts contain respondents born near the turn of the century (1900 1907). These individuals were 49-56 in 1956, and as they aged to 61-68 in 1968 their constraint levels increased sharply with age. Similarly, aging effects are more pronounced for the two youngest generations than they are for the "in-between" cohorts containing respondents between 33 and 48 years old during the twelve years of observation. Therefore, while aging effects hold across most cohorts, they are especially pronounced for both older and younger generations. Since the effect of maturation on belief system structure varies somewhat from one generation to another, it suggests that either social circumstances or historical events interact so as to facilitate consistency among social welfare attitudes as cohorts age.

For the two oldest generations composed of individuals who were $22-29$ in 1929, the Great Depression and its aftermath was obviously one such event having lasting influence on the structure of beliefs. In comparison to younger generations, these individuals are characterized by higher levels of constraint during the 1950s and 1960 s, by higher initial levels in their forties at the beginning of these sets of observations, and by the highest levels of all in 1968..$^{51}$ Although the data are necessarily incomplete, the oldest residual generations to the lower left of Table 2 (those born before 1899) passed through their formative years prior to the Depression and they are characterized by somewhat lower levels of constraint. Furthermore, the "middle age" generations (born in 1920-27) either cannot remember the Depression or did not witness it during formative years, nor did they appear to respond to the turmoil of the 1960s. These are "in-between" generations, both characterized by eight-year decreases in constraint levels. On the other hand, the "chil-

The 1972 SRC/CPS data include responses to an employment and a health insurance question, but both the wording differences and 7-point response categories make analysis statements particularly difficult. Non-response rates are higher for this type of question in 1972 and simple gamma coefficients are generally depressed; however, the same relative effects over time continue in 1972 , especially for the older generations. 
dren of the Depression" born in 1928-35 are the youngest cohorts, and they tend to begin with lower constraint levels as they enter mature life in the 1950 s, increasing in "ideology" as they mature through young adulthood in the 1960s.

While the above interpretation is cast mostly in event terms, the effects of aging must not be forgotten. It has a relatively common impact with the exception of the "middle ages" - a stable period less characterized by change in constraint and more so by inconsistencies and conflicts over social roles. The power and size of these cohorts is not measured here, yet it would surely be a fallacy to assume that "ideologies" predominate in recent years without taking this middle-American slice into account. The effects of aging, however, cannot be treated in isolation. While they are contrary to a more favored generational interpretation in politics, we cannot simply conclude that an "aging ideologue" hypothesis holds; indeed, the complex and mixed effects apparently operating in the deceptively simple cohort matrix require measurement beyond visual inspection.

In order to achieve the parsimony necessary for assessing the relative impact of generation and maturation influences, and in the absence of any single, widely accepted procedure, several alternatives methods are applied to the data in Table 2. The first is a simple measure of directional shift along cohort diagonals to test for aging effects. ${ }^{52}$ Where the change from one observation to another along a cohort supports an "aging ideologue" interpretation (i.e., an increase in constraint), a plus is recorded and a decrease is registered as a minus. The total of four-year differences with this procedure $=17+, 9$-, and 1 constant. Eight and twelve year differences are less susceptible to error fluctuations between adjacent samples and more indicative of longer range trends; they also suggest support for the aging interpretation (eight year $=12+, 16-$; twelve year $=8+, 1-$ ).

The above procedure is only a crude aid to visual interpretation since it treats neither magnitude of change nor relative effects. These characteristics may be captured by "coefficient fluctuation" models based on measures of homogeneity/ heterogeneity within rows and diagonals. ${ }^{53}$ Greater mean levels of fluctuation (heterogeneity) in lifestages (while age is constant) exhibit a generational effect, whereas a higher score for the cohorts (while generation is constant) shows an aging effect. The results of this test are reported in Table 3 ; they indicate nearly equal amounts (.326 and .318) of variation by row and diagonal, and no clear predominance of one effect over the other. A similar procedure may be followed with a correction for trend - based on the assumption that effects must be compared in light of overall shifts in the total population. ${ }^{54}$ The results of this procedure also appear in Table 3, where generational differences (lifestage fluctuation) exhibits slightly greater impact than aging (1.90 vs. 1.65$)$.

\footnotetext{
${ }^{8 n}$ For an example see Cutler, "Generation, Maturation and Party Affiliation."

${ }^{s 5}$ Since homogeneity within cohorts indicates differences between generations and fewer aging effects, and since homogeneity within rows or lifestages implies an aging effect in the absence of generational differences, net fluctuations in adjacent gammas for the rows may be compared to that in the diagonals in order to assess relative influences. The procedure therefore involves summing the absolute differences between adjacent coefficients for the rows (lifestages) and then deriving a mean level of fluctuation for all rows; the same procedure is followed for the diagonals. See ibid.

${ }^{84}$ Although there is some controversy over the utility of trend corrections, it is intuitively appealing to attempt a measure of, e.g., cohort shift, above and beyond that already evident in the population. That is, with an increase in constraint for the total sample, it is particularly meaningful if a cohort or lifestage change between adjacent coefficients increases dramatically. One way to measure this and, in effect, control for trend, is to derive standardized $Z$ scores for each column (observation points) reflecting the total constraint value for that year. The fluctuation measure is then applied to the $\mathrm{Z}$ scores. See Hyman, "Secondary Analysis," p. 285; and examples in Crittenden, "Aging and Party Affiliation"; Neal Cutler, The Alternative Effects of Generations and Aging Upon Political Behavior (Oak Ridge, Tenn.: Oak Ridge National Laboratory, 1968).
} 
Further evidence of nearly equivalent effects is found through variations on a regression model presented in Table 3. A linearity/heterogeneity test reflects the simple correlation coefficient $(r)$ and associated regression coefficient (b) as each set of cohort and lifestage values is correlated with time and subsequently averaged. A similar procedure yields a "trend test" by correlating observations within cohorts

Table 3. Measures of Aging and Generational Effects: Summary of Alternative Hypothesis-Testing Models

\begin{tabular}{|c|c|c|c|c|}
\hline & \multicolumn{3}{|c|}{$\begin{array}{c}\text { Average Deviation Proportion Model } \\
\text { ADP }\end{array}$} & \multirow{2}{*}{ GADP } \\
\hline & $1956-60$ & $1960-64$ & $1964-68$ & \\
\hline \multicolumn{5}{|l|}{ Total Sample } \\
\hline Cohorts & .090 & .265 & .151 & .169 \\
\hline Lifestages & .121 & .294 & .146 & .187 \\
\hline I.S. Correction & .121 & .171 & .117 & .136 \\
\hline \multicolumn{5}{|l|}{ Low Education } \\
\hline Cohorts & .193 & .918 & .326 & .479 \\
\hline LIfestages & .234 & .785 & .423 & .481 \\
\hline L.S. Correction & .234 & .502 & .392 & .372 \\
\hline \multicolumn{5}{|l|}{ HIgh Education } \\
\hline Cohorts & .224 & .363 & .291 & .293 \\
\hline Lifestages & .197 & .558 & .351 & .369 \\
\hline L.S. Correction & .197 & .290 & .354 & .278 \\
\hline
\end{tabular}

Coefficient Fluctuation Models

\begin{tabular}{|c|c|c|c|}
\hline & $\begin{array}{l}\text { Total } \\
\text { Sample }\end{array}$ & $\begin{array}{c}\text { Low } \\
\text { Education }\end{array}$ & $\begin{array}{c}\text { High } \\
\text { Education }\end{array}$ \\
\hline $\begin{array}{l}\text { No Trens Correction ( } \overline{\mathrm{X}} \text { gamma) } \\
\overline{\mathrm{x}} \text { Cohort Fluctuation } \\
\overline{\mathrm{X}} \text { Lifestage Fluctuation }\end{array}$ & $\begin{array}{l}.326 \\
.318\end{array}$ & $\begin{array}{l}.434 \\
.577\end{array}$ & $\begin{array}{l}.380 \\
.523\end{array}$ \\
\hline $\begin{array}{l}\text { Trend Correction }(\overline{\bar{X}} \text { Z scores }) \\
\overline{\bar{X}} \text { Cohort Fluctuation } \\
\overline{\mathrm{X}} \text { Lifestage Fluctuation } \\
\text { L.S. Correction }\end{array}$ & $\begin{array}{l}1.65 \\
1.90 \\
1.61\end{array}$ & $\begin{array}{l}1.27 \\
2.08 \\
1.81\end{array}$ & $\begin{array}{l}1.64 \\
1.98 \\
1.62\end{array}$ \\
\hline
\end{tabular}

Regression/Corxelation Mode1

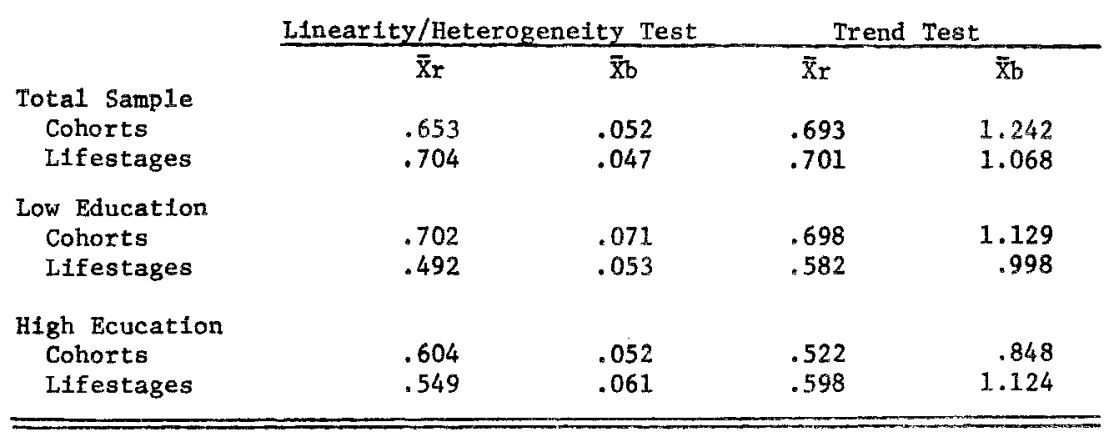

(and then lifestages) with the trend values for the total sample. Although both sets of procedures are more susceptible to error under conditions of few observations, they at least provide a descriptive handle for alternative effects through time series measures which sharpen the eye. ${ }^{55}$ As Table 3 indicates, the measures again show nearly equal effects.

\footnotetext{
${ }^{5 *}$ For a general treatment of this class of techniques see Kirkpatrick, Quantitative Analysis of Political Data, pp. 385-406.
} 
A final measure of relative effects employs a slightly different logic than those above, yet it still achieves a trend "correction." The procedure as developed by Klecka yields deviation proportions reflecting the differences between observed and expected values. ${ }^{56}$ The deviation values are presented in Table 3 and are consistent with the other measures of relative effects: cohort homogeneity/consistency is only slightly greater than lifestage consistency (.169 vs .187).

While all of the summary measures presented in Table 3 show nearly equal aging and generation influences on constraint shifts, they also suggest a slight edge for generational interpretations. This empirical edge, however, is due to a "deviant" pair of constraint coefficients for 21-24 year olds in 1964 and 1968..$^{57}$ When these unusually high deviation proportions are omitted from the lifestage analysis, its GADP value reduces from .187 to .136 - giving a slight edge to aging effects. A similar "correction" was applied to the other de-trending measure utilizing $\mathrm{Z}$ scores by omitting the first lifestage from the calculations: the result was a reduction of the mean lifestage $\mathrm{Z}$ score from 1.90 to 1.61 , again throwing the empirical weight to an aging interpretation. Such manipulations, however, continue to exhibit relative similarity of effects.

\section{Level of Educational Attainment and Age-Related Differenges in Constraint}

Among the various factors posited as influencing the structure of belief systems, level of educational attainment (as reflecting information levels) is the most commonly tested variable. Early research followed a high information-high educationhigh consistency theme and was bolstered by findings related to constraint, ${ }^{58}$ political elites, ${ }^{50}$ and relationships between abstractions and specifics. ${ }^{60}$ Contrary evidence has since developed in support of lower consistency levels among higher education strata; ${ }^{61}$ borrowing explanatory frameworks from research linking higher education, inconsistency, tolerance for ambiguity, a tendency to delay states of congruity, cognitive complexity, information levels, understanding and cognitive flexibility vs. findings associating balance and consistency with rigidity, oversimplification and lower education. ${ }^{62}$ Finally, there is recent supporting evidence of either

The procedure computes an expected value for each sequentially adjacent matrix entry (cohorts and lifestages) on the assumption that each shift will occur by the same proportion as that in the total sample. Deviations between expected and observed values (deviation proportions) are calculated for each sequential pair of coefficients (for both lifestages and cohorts) to measure the influence of factors intrinsic to each lifestage/ cohort between adjacent observation periods. The absolute value of deviation proportions is then averaged (ADP = average deviation proportion) between surveys, with a final grand average (GADP) as a summary statistic. For the algorithms see Klecka, "Applying Political Generations," p. 366; also William R. Klecka, "Distinguishing Life-Cycle and Generation Effects in a Cohort Analysis of Sample Survey Data," unpublished manuscript, University of Cincinnati, 1973.

${ }^{57}$ The isolated case responsible for a dip in mean gamma is that based on the relationship between aid to education attitudes and employment guarantees for 21-24. year olds in 1968. Note that some argue for excluding all off-diagonal matrix components, see Miller, Brown, and Raine, "Social Conflict."

Converse, "The Nature of Belief Systems in Mass Publics."

${ }^{59}$ Herbert McClosky, "Consensus and Tdeology in American Politics," American Political Science Review, 58 (1964), 361-82.

"James W. Prothro and Charles M. Grigg, "Fundamental Principles of Democracy: Bases of Agreement and Disagreement," Journal of Politics, 24 (1960), 276-94.

${ }^{61}$ Kirkpatrick, "Conflicts in Political Attitudes"; Peter W. Sperlich, Conflict and Harmony in Human Affairs: A Study of Cross-Pressures and Potitical Behavior (Chicago: Rand McNally, 1971), p. 16; also see Samuel A. Kirkpatrick, "Extended Sources of Political Opinion Consistency," unpublished manuscript, University of Oklahoma, 1970.

"William A. Scott, "Cognitive Complexity and Cognitive Flexibility," Sociometry, 25 (1962), 405-14; William A. Scott, "Cognitive Complexity and Cognitive Balance, Sociometry, 26 (1963), 66-74; O. J. Harvey, David E. Hunt, and Harold M. Schroder, Conceptual Systems and Personality Organization (New York: Wiley, 1961). 
(1) few differences in constraint between levels of education, ${ }^{63}$ (2) slight indications of curvilinearity, ${ }^{64}$ or (3) experimentally confirmed curvilinear relationships with constraint highest at the extremes of low and high education. ${ }^{65}$

Although empirical evidence and theoretical justifications for the possible relationships between constraint and education level vary, any effect may be particularly important in the present analysis since education and age are correlated. Increases in overall constraint levels may result from generational changes in education levels. It may be that older generations are more constrained and less educated than younger generations, or constraint may increase with age, as does education. In general, any specific confounding effect of education may change conclusions presented earlier. Therefore, a tabular control for level of educational attainment is introduced for the cohort matrix in Table 2 and presented in Tables 4 and 5. Increased sampling error precludes the division of education into more than two categories (high school degree or more vs. less than high school degree) to capture greater variation and potential curvilinear effects. Error is also a problem within various components of each submatrix, as suggested by several higher

Table 4. Cohort Matrix of Social Welfare Attltude Constraint ( $\overrightarrow{\mathrm{X}}$ gamma) for Low Education Respondents: 1956-1968

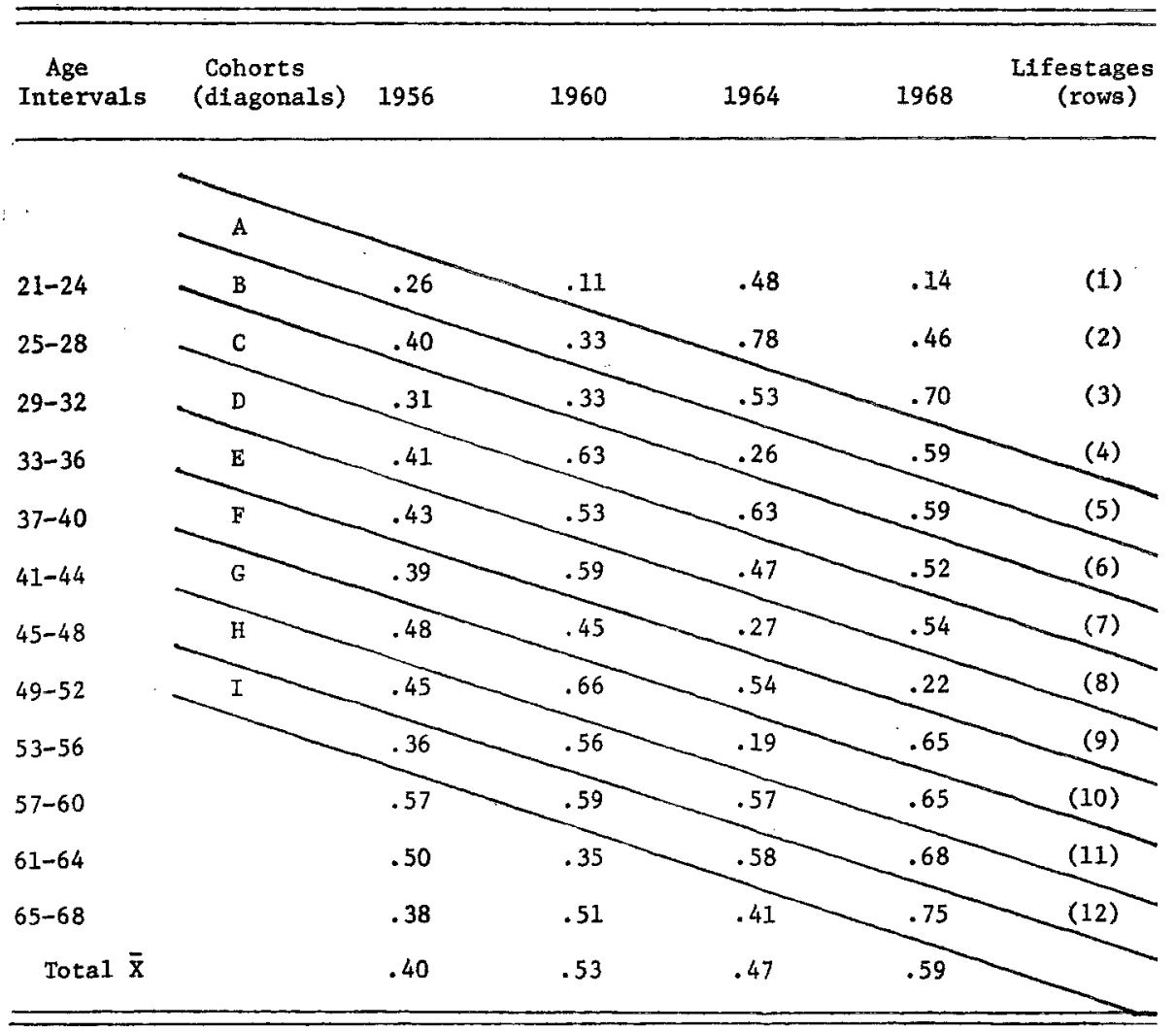

"Bennett, "Consistency"; Nie and Andersen, "Mass Belief Systems."

${ }^{34}$ Ibid.; David L. George, "An Experimental Study of Attitudinal Conflict and Political Involvement in a Voting Context," Experimental Study of Politics, 1 (1971), 35-64.

${ }^{s 5}$ For evidence and theoretical elaboration see Warren H. Jones and William W. Rambo, "Information and the Level of Constraint in a System of Social Attitudes," Experimental Study of Politics, 2 (1973), 25-39. It should also be noted that, with the exception of Bennett, "Consistency," and Nie and Andersen, "Mass Belief Systems," these are single year studies characterized by low comparability in measures of consistency and constraint. 
Table 5. Cohort Matrix of Soctal welfare Atltude Constraint ( $\overline{\mathrm{X}}$ gamma) for High Education Respondents: 1956-1968

$\begin{gathered}\text { Age } \\ \text { Intervals }\end{gathered}$
$\begin{gathered}\text { Cohorts } \\ \text { (diagonals) }\end{gathered}$ 1956

levels of fluctuation for both education categories and both age-related effects (see Table 3).

On the whole, the findings which result from this exercise suggest minimal impact for educational attainment on the relationships evident for age-related differences in the total population (Table 2). The overall mean gammas reported at the bottom of Tables 4 and 5 reinforce Bennett's conclusion based an only two observations: that level of education does not differentiate the consistent from the inconsistent in the social welfare policy domain. ${ }^{66}$ Indeed, the gamma values for corresponding years are very similar between high and low education groups. Furthermore, the characteristics of the total cohort matrix (Table 2) tend to be reflected in each submatrix, and there are few marked differences between levels of education. While the low education group fluctuates more on both measured effects (Table 3 ), the patterns for the high education matrix are not necessarily more interpretable (e.g., linear). Both levels of education are nearly equally supportive of aging trends ${ }^{67}$ and generational effects. Perhaps the major difference is one suggesting that generational impact is greater for the less educated, i.e., that less educated cohorts are less susceptible to aging effects, less influenced by change during the life cycle and more responsive to events which may divide generations. Yet there is an important exception to this trend for older generations: an increase

Bennett, "Consistency," p. 561.

${ }^{\circ 7}$ The plus and minus test for aging effects in the diagonals yields the following 4-year, 8-year, and 12-year differences respectively; for low education: $17+, 19_{-}, 1$ constant; $12+, 6-; 8+, 1-;$ for high education: $16+, 11-; 10+, 7-, 1$ constant; $8+, 1-$. 
in constraint with aging is pronounced in the older generations with lower education. $^{68}$ Again, there is a blend of effects whereby the less educated of the Depression generation are characterized by higher constraint levels and increases over their life cycle during the 1950s and 1960s.

\section{Conclusion}

With previous research on constraint or interrelatedness between attitudes on political issues as a departure point, the foregoing analysis extends measures of social welfare issue constraint over a twelve-year period in recent American history. The findings support previous research indicating general increases in modal consistency in more recent years. It then reports the effects of two components of the age variable on attitude structure: generational differences and changes over the life cycle. Both effects are present in constraint shifts: generational differences with older cohorts more constrained and aging effects across most cohorts. The mixture of effects is evident in a tendency for both the younger and older (rather than middle) generations to increase in constraint with aging. Since political scientists rely heavily on generational interpretations of politics to the exclusion of life cycle changes, the equipollence of aging effects on constraint levels is an unusual finding normally obscured through cross-section analysis. In addition, the introduction of controls for level of educational attainment shows few constraint differences across both high and low educational strata. A cohort analysis for each education level confirms the similarity of generational and maturational effects - total population effects tend to be reflected in each education group. Nevertheless, a generational influence is evident among low education cohorts. With the exception of older generations, low education birth cohorts are less susceptible to aging effects and more likely to reflect generation-related phenomena.

The findings suggest a more cognitively healthy polity than indicated in previous research. The modal level of attitude constraint among social welfare issues has generally increased and appears to respond rather predictably to salient events in the political environment - but this is blended with increasing cognitive organization capabilities within various segments of the population progressing through the life-cycle. Social welfare issues may be more salient to the aged, yet they continue to divide political partisans in the United States ${ }^{69}$ and are likely to be characterized by event-related battle lines in a political system faced with increasing demands from older segments of society. ${ }^{70}$

The data presented above defy simplistic interpretations which espouse overarching and uniform influences for particular events, periods, or aging processes. A complex mix of influences shapes the structure of belief systems and shifts in constraint, and only several of these possible influences have been investigated here: age-related differences and educational levels. Future research might focus on other influences and structuring elements, such as political interest and information. Age may often be a surrogate for more unique influences; nevertheless, the examination of age-related factors through cohort analysis is a substantial improvement over cross-sectional inferences. Considerable theoretical work is also necessary for

\footnotetext{
${ }^{68}$ This is why the mean cohort correlation coefficient for low education is higher, i.e., .702 . At first glance this suggests that less educated cohorts progress in constraint monotonically with time; whereas the value is high due to nearly perfect correlations for the last two older generations. Also note that both levels of educational attainment are almost equally correlated with trend.

Richard W. Boyd, "Popular Control of Public Policy: A Normal Vote Analysis of the 1968 Election," American Political Science Review, 66 (1972), 429-50; Kirkpatrick and Jones, "Vote Direction and Issue Cleavage in 1968."

"For development of this thesis see Neal E. Gutler, "The Future Role of Age in Politics: Demographic, Social Psychological, and Political Factors," unpublished paper presented at the Annual Meeting of the American Political Science Association, 1974.
} 


\section{Western Political Quarterly}

developing an interactive theory applicable to both individual and group-level analyses of change. Although we have shown that a variety of analysis models may be applied to cohort matrices to sharpen visual inspection and enable more parsimonious judgments about maturation and generational effects, sophisticated multivariate models are essential. Continued attention to ideology-related phenomena and their mix with generational and maturational processes over longer time periods will provide clues to the relationship between changing mass publics and their dynamic environment. 